\title{
Identification and Estimation of Metoclopramide in Rat Blood by High Performance Liquid Chromatography
}

\author{
Zena Sattam Hamad and Basil Mohammed Yahya \\ Department of Pharmacology, College of Pharmacy, University of Mosul, Iraq.

$\frac{\text { Accepted }}{r .0 . r \cdot T r} \quad \frac{\text { Received }}{\text { ro.T.r.Tr}}$

\section{ABSTRACT}

Objectives: to evaluate a rapid and sensitive high performance liquid chromatographic method for the determination of metoclopramide in rat serum.

Methods: The assay was performed after liquid-liquid extraction with sodium hydroxide and dichloromethane.

Results and conclusion: Chromatographic separations were performed on $\mathrm{C}_{\text {is }}$ stationary phase with a mobile phase composed of acetonitrile : $1 \%$ triethyleamine $(0 \cdot: 0 \cdot, \mathrm{v} / \mathrm{v})$ at $\mathrm{pH}(\urcorner, \wedge)$. Analytes were detected at wave length of $Y \mathrm{~V} \cdot \mathrm{nm}$. This method was validated for specificity and linearity with a correlation coefficient, $r=\cdot 9$.

Key words: metoclopramide, chromatographic method, HPLC, rat serum.

$$
\begin{aligned}
& \text { الخلاصة } \\
& \text { الهذف : يوضح البحث سر عة و حساسية طريقة الاستشر اب السائل عالي الاداء المنجزة لقياس تركيز الـ } \\
& \text { Metoclopramide }
\end{aligned}
$$

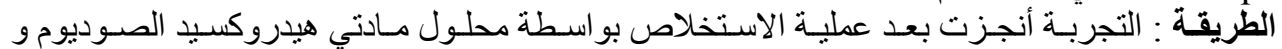

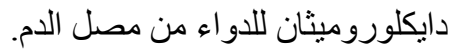

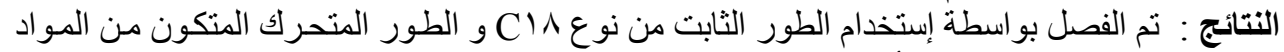

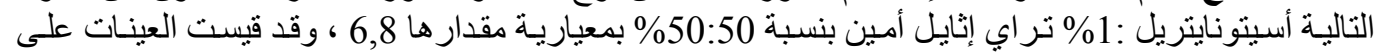

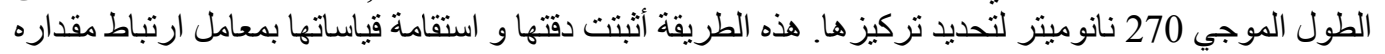

$$
\begin{aligned}
& \text { وصف في هذا البحث طريقة سريعة و حساسة وهي طريقة الاستشر اب السائل عالي الأداء لقياس تركيز } \\
& .0,94 \\
& \text { دو اء الـ Metoclopramide في مصل الدم للجرذان في المختبر. }
\end{aligned}
$$

M etoclopramide is an antiemetic and gastroprokinetic agent ${ }^{\prime}, r$. It is commonly used to treat nausea and vomiting, to facilitate gastric emptying in people with gastroparesis, and as a treatment for the gastric stasis often associated with migraine headaches ${ }^{r}$. It is also used as a preventive medicine for cancer chemotherapy -induced

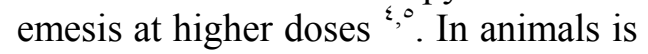
commonly used to prevent vomiting and also used as a gut stimulant ".

Due to the applications of metoclopramide in clinical and experimental medicines, many methods are available for its determination in biological fluids and dosage forms ${ }^{\vee}$. Both the United States Pharmacopoeia (USP,,$\ldots \cdot)^{\wedge}$ and the British Pharmacopoeia (BP, 1991) recommend a non aqueous acid-base titration with potentiometric detection of the end-point for the evaluation of the raw material of metoclopramide from its dosage forms. USP recommends HPLC method and the BP describes spectrophotometric method of analysis ${ }^{\circ}$.

Normal-phase HPLC using a silica column and reversed-phase (RP) HPLC or ion-pair HPLC methods on octadecyl column were described for the analysis of metoclopramide in biological fluids '. However, to reduce consumption of more organic solvents, and reducing long run time, a modified HPLC technique with manipulation of the conditions was applied.

The present study describes a sensitive, specific and rapid sample 
preparation assay with short run time of 1 minutes for determining metoclopramide in rat serum by using HPLC with no interference from it's metabolites.

\section{Materials and methods \\ Chemicals and reagents}

Purified free base of metoclopramide for research purposes was provided by NDI/Nenava Drug Industry/Iraq . All solvents used were HPLC grade, and all chemicals were analytical grade: HPLC-grade acetonitrile Scharlau/Spain, HPLCgrade triethylamine Scharlau/Spain and deionised water NDI/Iraq. Analytical grade sodium hydroxide and dichloromethane were from GCC company/UK.

\section{Instrumentation}

The analyses were carried out using a chromatographic system from Shimadzu Corporation (Japan). This instrument consisted of a pump, a UVvisible detector, a system controller, and a manual injector. Software was used to control the LC system and data acquisition.

Analyses of metoclopramide were performed at room temperature on a (GL Sciences Inc.) C C^ column (

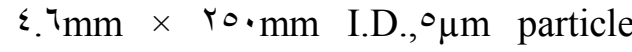
size) under isocratic conditions using acetonitrile : $1 \%$ triethyleamine $(\bullet \cdot: \bullet \cdot, \mathrm{v} / \mathrm{v})$ as mobile phase at $\mathrm{pH}(\urcorner . \wedge)$ and flow rate of $1 . r \mathrm{~mL} / \mathrm{min}$. UV detector was operating at $r v \cdot n m$. The mobile phase was filtered through a Millipore membrane filter $\left(\cdot\left\{{ }^{\prime} \mu \mathrm{m}\right)(\right.$ Steril-R/USA) and degassed ultrasonically prior to use.

Preparation of stock solution and working standards

Stock solution of metoclopramide was freshly prepared in mobile phase solution at the concentration of $(1 \cdot \mathrm{mg} / \mathrm{l} \cdot \mathrm{mL})$. Working standards of metoclopramide were freshly prepared in the concentrations of $\left(\cdot .1 r_{0}, \cdot r_{0}\right.$, $\because \circ, 1, r \mu \mathrm{g} / \mathrm{mL})$ and made by the dilution of the stock solution with mobile phase.

\section{Animals and Sample preparation}

Adult albino rats were used in this work that have been taken from animal house of the College of Veterinary Medicine, University of Mosul. This study was carried out on ${ }^{\circ}$ animals (male and female), their weights were between ro.ro. g. The work was done at laboratory of the College of Veterinary Medicine, University of Mosul. One $\mathrm{ml}$ of blood samples were collected from healthy adult rats, not taking any kind of drug, in non heparinized glass tubes, then blood samples were collected from each animal after $(10, r \cdot, r \cdot \mathrm{min})$ of administration of therapeutic dose of metoclopramide $\left({ }^{\circ} \mathrm{mg} / \mathrm{kg}\right)$ was given by i.p. route to each animal ${ }^{1,7}$. The blood samples were centrifuged at r...rpm for $10 \mathrm{~min}$ and the serum was frozen and stored at $-r \cdot{ }^{\circ} \mathrm{C}$, no longer than $V Y h$.

Extraction of the samples (liquidliquid extraction) LLE

Serum $(r \cdots \mu \mathrm{L})$ was mixed with, sodium hydroxide $I M(0 \cdot \mu \mathrm{L})$ in a $1 \cdot \mathrm{mL}$ stoppered test tube and the tube was vortexed for aboute $r \cdot$ seconds. The solution was mixed with dichloromethane ( $r \mathrm{~mL})$, vortexed at high speed for Imin. The resultant mixture was centrifuged at $\leqslant \cdots \mathrm{rpm}$ for ${ }^{\circ}$ min. The aqueous layer was aspirated to a waste and the organic layer was transferred to a clean tube. The tube containing the organic layer was placed in a water bath $\left(0 .{ }^{\circ} \mathrm{C}\right)$ and evaporated to dryness. The residue was reconstituted in $(1 \cdots \mu \mathrm{L})$ of mobile phase prior to injection into the chromatograph for analysis ".

\section{Chromatographic conditions}

Several chromatographic conditions, such as mobile phase, type of column and its length, mobile phase $\mathrm{pH}$, flow 
rate, temperature and volume of injection were studied to obtain a satisfactory chromatographic separation (good resolution and efficacy) for the compound. In addition, the total time required for the analysis was also an important factor because the analysis could be unfeasible since interfering compounds could elute close to the metoclopramide, modifications were performed in order to reduce the analysis time.

Various solvents or mixture of solvents at different compositions were used to extract the metoclopramide from rat serum using LLE.

To optimize the HPLC parameters, one mobile phase composition was tried :

Acetonitrile : $\quad 1 \%$ Triethylamine $(0 \cdot: 0 \cdot, \mathrm{v} / \mathrm{v})^{r}$.

The buffer solution : about $1 \cdot \mathrm{mL}$ of triethylamine was diluted to $1 \mathrm{~L}$ with deionised water to obtaine $1 \%$ triethylamine buffer solution.

A mixture of Acetonitrile and 1\% triethylamine in the ratio of $0 .: 0 . \%, \mathrm{v} / \mathrm{v}$ was prepared at $\mathrm{pH}(1) . \mathrm{r})$. The peak of triethylamine interfered with the peak of metoclopramide and changing the flow rate did not separate between the two peaks but, adjusting the $\mathrm{pH}$ to $\urcorner. \wedge$ resulted in a typical peak for metoclopramide with a retention time $r .{ }^{\circ} \mathrm{min}$ without interfering with any other compounds .

\section{Results}

A satisfactory separation and good peak symmetry was found in a mixture of acetonitrile : $1 \%$ triethylamine in the ratio of $0 .: 0 . \%, \mathrm{v} / \mathrm{v}$ at a $\mathrm{pH}(\urcorner . \wedge)$ and flow rate of $1 . r \mathrm{~mL} / \mathrm{min}$. The optimum wavelength for detection was set at $r V \cdot n m$ at which much better detector response for drug was obtained. The retention time was $r .{ }^{\circ} \mathrm{min}$ for metoclopramide and no interferences were observed in formulation sample, also with a better reproducibility.

Quantification was achieved with UV detection at $r V \cdot n m$ based on the peak area. Better resolution of the peaks with clear base line separation is found as shown in Table. ',Fig.' and Fig. ${ }^{\text {. }}$.

Table. I Optimized chromatographic conditions for estimation of metoclopramide

\begin{tabular}{|c|c|}
\hline Mobile phase & $\begin{array}{c}\text { Acetonitrile : } 1 \% \text { triethylamine } \\
0 \cdot: 0 \cdot \%, \mathrm{v} / \mathrm{v}\end{array}$ \\
\hline Mobile phase pH & 7.1 \\
\hline Pump mode & Isocratic \\
\hline Diluent & Mobile phase \\
\hline Column & $\begin{array}{l}\text { GL Sciences Inc. C } \backslash \wedge \text { column( }\{.7 \times \\
\left.\text { Ү०. } \mathrm{mm},{ }^{\circ} \mu \mathrm{m}\right)\end{array}$ \\
\hline Column temp & Ambient \\
\hline Wavelength & $r V \cdot n m$ \\
\hline Injection volume & $r \cdot \mu \mathrm{L}$ \\
\hline Flow rate & 1. $. \mathrm{mL} / \mathrm{min}$ \\
\hline Run time & $r^{\prime} \min$ \\
\hline Retention time & $r .0 \mathrm{~min}$ \\
\hline
\end{tabular}




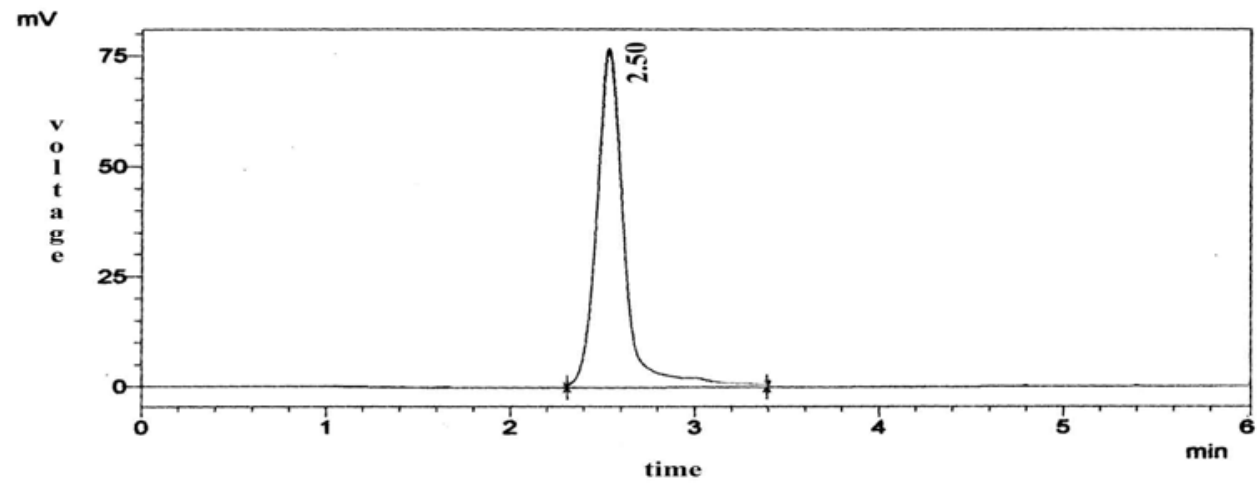

Figure. ' Chromatograms of validation of the method

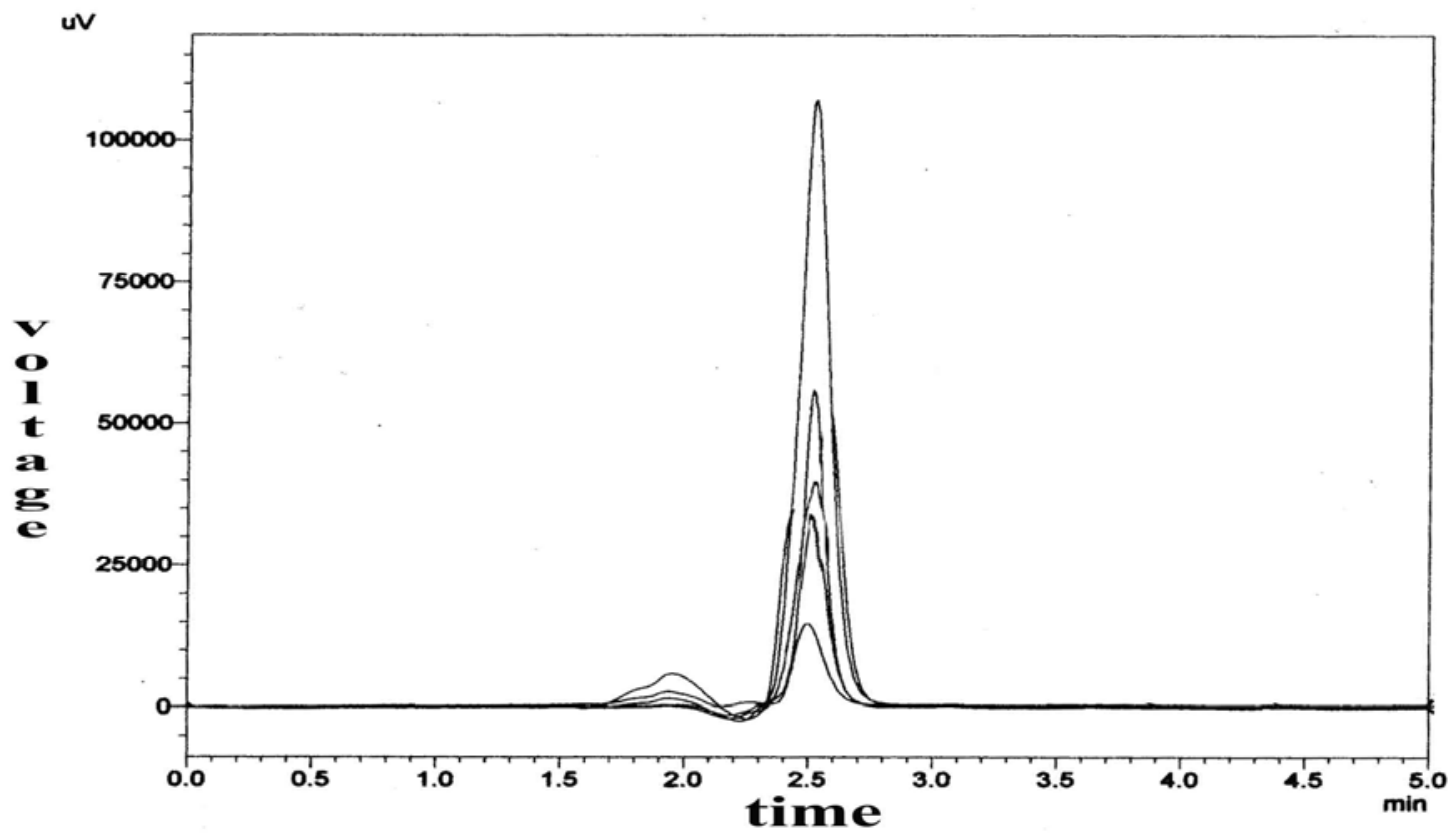

Figure. ${ }^{r}$ Chromatograms of standards solution with different concentrations

\section{Specificity}

The specificity of method was performed by comparing the chromatograms of blank, standard and sample. It was found that there was no endogenous interference and also found good correlation $(\mathrm{r}=\cdot .9 \varepsilon)$ between the retention times of standard and sample are shown in Table. $r$, Fig. ${ }^{\sim}$, Fig. $\_$and Fig. ${ }^{\circ}$.

Table $r$ :specificity study

\begin{tabular}{|c|c|}
\hline Name of the solution & Retention time in Min \\
\hline Blank & No peak \\
\hline standard & r.o \\
\hline sample & r.o \\
\hline
\end{tabular}




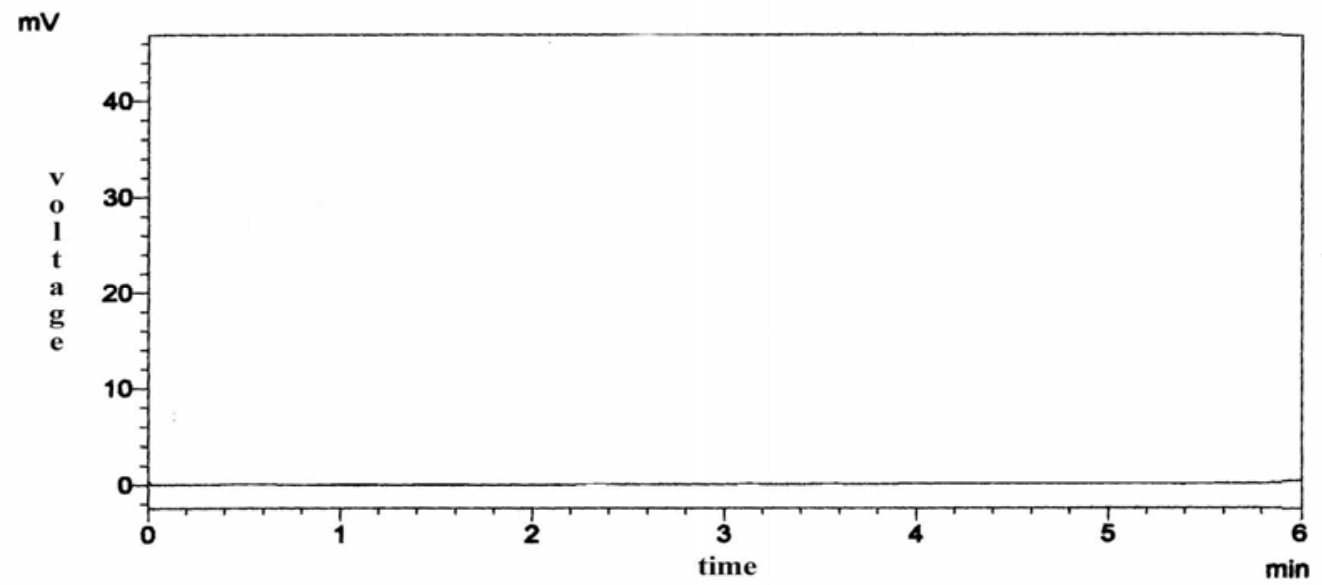

Figure. r Chromatogram of blank

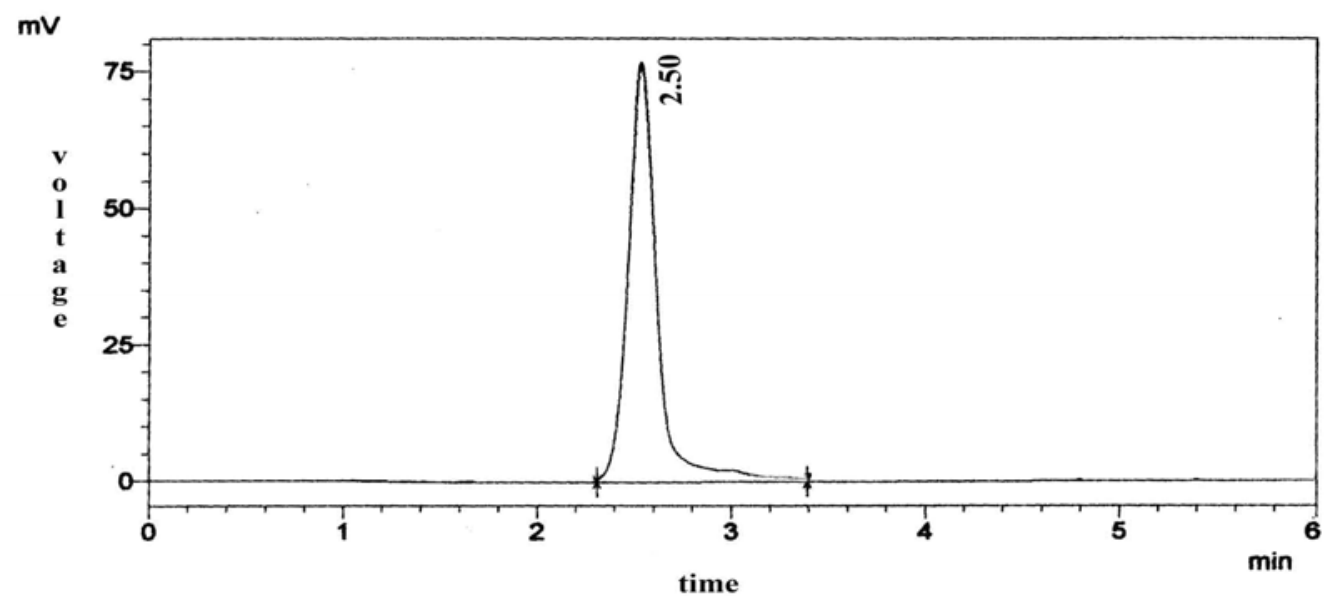

Figure. \& Chromatogram of standard metoclopramide

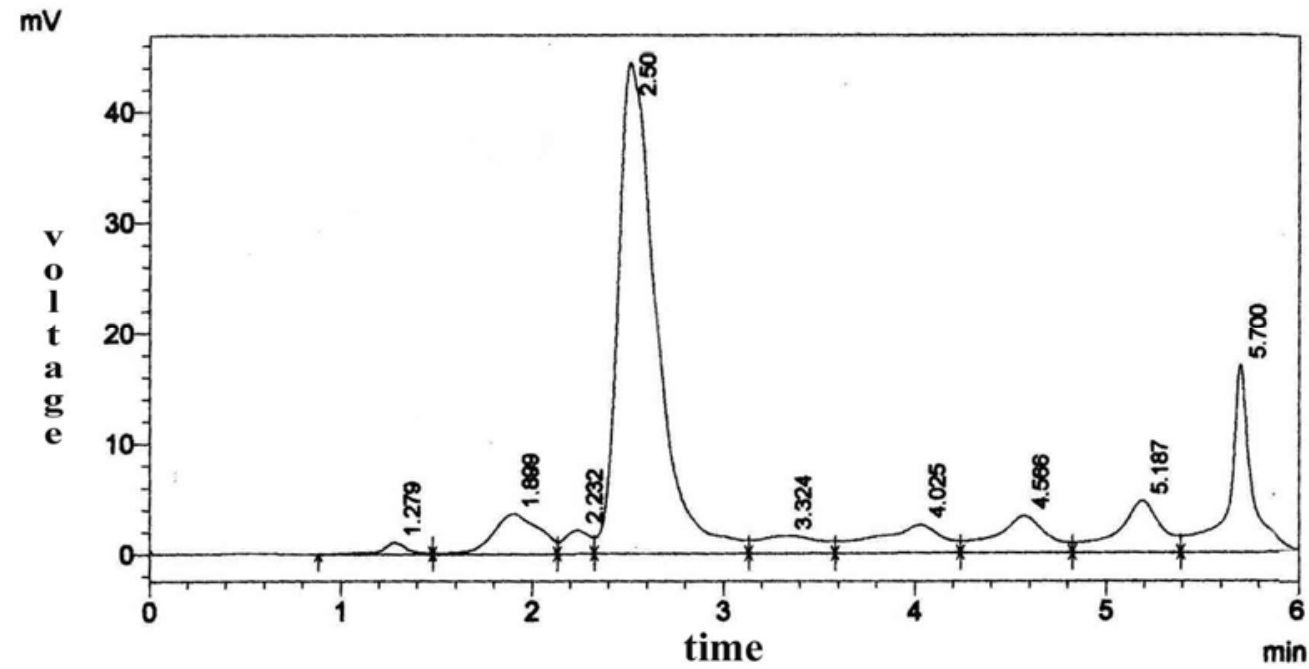

Figure. ${ }^{\bullet}$ Chromatogram of sample Linearity 
Linearity was performed by preparing standard solutions of metoclopramide at different concentration levels including working concentration mentioned above. Twenty micro liters of each concentration was injected in duplicate into the HPLC system. The response was read at $r v \cdot n m$ and the corresponding chromatograms were recorded. From these chromatograms, the mean peak areas were calculated and linearity plot of concentrations over the mean peak areas were constructed. The regression of the plot was computed by least square regression method. Linearity results were presented in (Table. ${ }^{r}$ ), calibration plot was shown in (Fig. ${ }^{\top}$ ) and calibration plots of the samples was shown in (Fig. $\vee$ ).

Table. ${ }^{\sim}$ Linearity Results

\begin{tabular}{|c|c|c|}
\hline Level & $\begin{array}{c}\text { Concentration of } \\
\text { metoclopramide in }(\mu \mathrm{g} / \mathrm{mL})\end{array}$ & Mean peak area $(\mathrm{mV})$ \\
\hline Level-1 & $.1 T_{0}$ & 15.700 .0 \\
\hline Level-r &. ro & $\varepsilon \cdot V V 00$ \\
\hline Level-r & .0 & STr... \\
\hline Level-乏 & 1 & $0 \wedge .7 Y \wedge .0$ \\
\hline Level-o & r & 1.9 YVAI \\
\hline $\begin{array}{c}\text { Range: } \cdot 1 \text { ro } \\
\text { to } r\end{array}$ & $\begin{array}{c}\text { Slope } \\
\text { Intercept } \\
\text { Correlation coefficient }\end{array}$ & $\begin{array}{l}r \leq 9.7 V . r \\
\varepsilon \cdot \leq 101.9 \\
.9 \leq \varepsilon V\end{array}$ \\
\hline
\end{tabular}

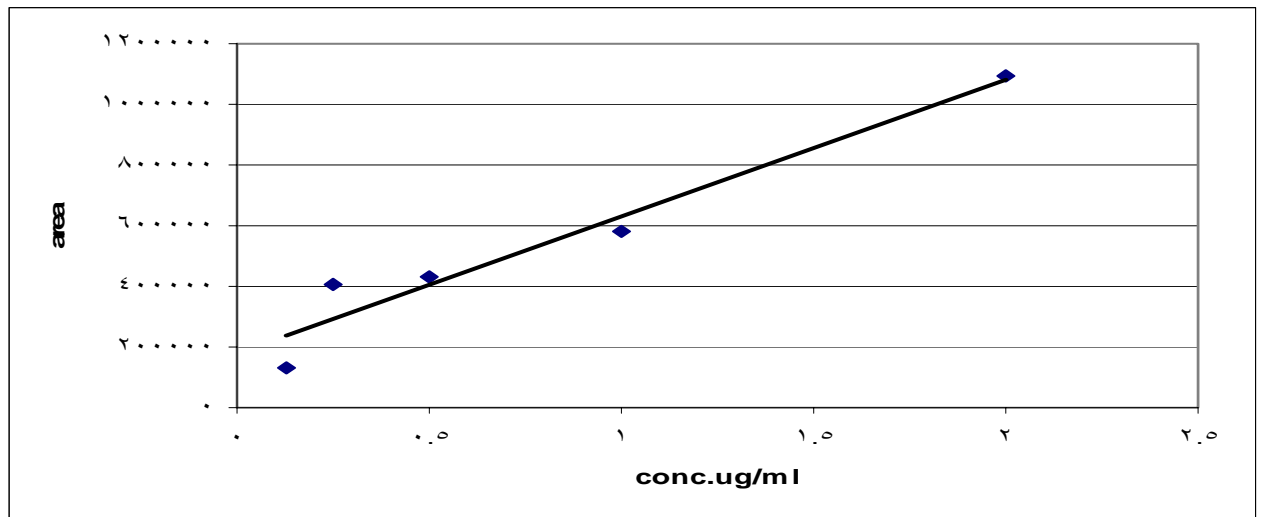

Figure. 7 Calibration plot for metoclopramide on $\mathrm{X}$ axis concentration of sample $(\mu \mathrm{g} / \mathrm{mL})$, on $\mathrm{Y}$ axis peak area response $(\mathrm{mV})$ 

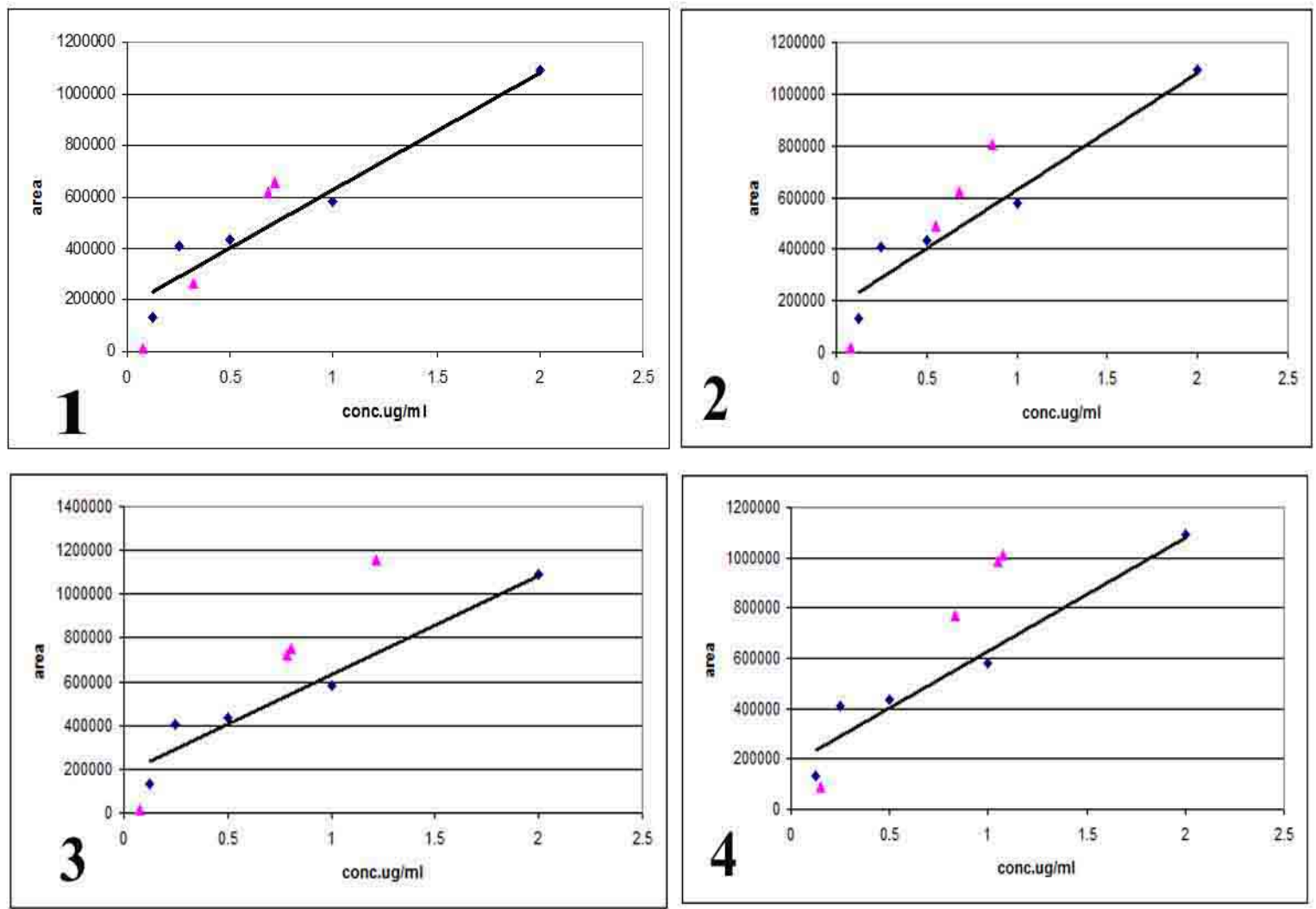
$\Delta$ concentration of samples
concentration of standards

$(1,2,3,4,5)$ the number of animal used

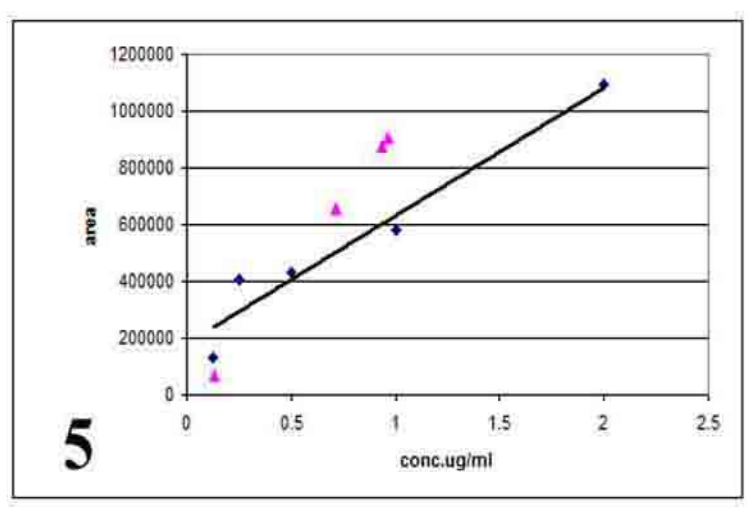

Figure. $\vee$

- Calibration curves were found to be linear with correlation coefficient $(\cdot .9 \leqslant \leqslant \vee)$, the intercept and the slope values were found to be $(\varepsilon \cdot\{\wedge 01.9)$ and $(Y \leq q, T V, r)$ respectively.

- Calibration plots for metoclopramide plasma concentration-area at $(\cdot, 10, r \cdot, 7 \cdot \min )$ after i.p. administration of the drug in ${ }^{\circ}$ animals. 


\section{Discussion}

Many analytical methods reported for the quantification of Metoclopramide in dosage forms and in biological fluids are various chromatographic procedures, gas chromatography/mass spectrometry (GC/MS) and high performance liquid chromatography (HPLC) methods with UV, fluorescence or electrochemical detection have been reported ", ir,

The performance of (HPLC) instruments has been remarkably progressed, and plays a conspicuous role in analysis of medicaments in formulations and biological samples. It's sensitivity ranging from microgram to picogram level. Hence, current HPLC methods for determination of medicament in biological sample are described $^{\prime r}$.

The chromatographic mobile phase composition is a critical factor for the separation of monitored compound and impurities of biological fluids. The reported mobile phase (acetonitrile : $1 \%$ triethyleamine buffer

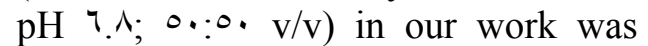
optimized primarily for rapid and interference-free chromatograms of serum extracts. In (Fig. ${ }^{\text {) }}$ ) shows representative chromatogram of extracted drug-free serum, and (fig. ${ }^{\circ}$ ) serum sample taken from rat after i.p. administration of ${ }^{\circ} \mathrm{mg} / \mathrm{kg}$ metoclopramide. A comparison of figures $\left({ }^{r}\right)$ and $\left({ }^{\circ}\right)$ indicates that metoclopramide peaks are free from matrix interference. Using the chromatographic conditions described, metoclopramide was well resolved with mean retention time of $r .0$ min.

Least-squares regression calibration curve was found to be linear at serum concentrations between $(\cdot) r_{0}$ to $\left.r \mu \mathrm{g} / \mathrm{mL}\right)$ of metoclopramide. The mean linear regression equation of the peak area ratios (y) vs. drug concentrations (x) of metoclopramide was typically of the from $y$ $=\varepsilon 0 r\left|. \varepsilon_{X}+\right| \vee \wedge r \leqslant r$. the mean correlation coefficient, $r$ was generally $>\cdot .9 \leq \leqslant \vee$.

Several workers r,,,$\xi$ have described methods for analysis of metoclopramide in pharmaceutical dosage form and its use in pharmacokinetic studies.

In this work the described reversed-phase high-performance chromatographic method is sensitive, accurate and rapid and could be reliable alternative to other separation methods for the analysis of metoclopramide. The procedure has been successfully applied to quantitative determination of metoclopramide in rat serum, and suitable for our laboratory conditions.

\section{References}

'.Nissen D. Mosby's Drug Consult. Missouri USA:Mosby,Inc. ${ }^{\cdots} \cdot r$. http://www.mosbysdrugconsult. com

r. Avula SK, Babu N. Development and validation of LC method for the analysis of metoclopramide in pharmaceutical dosage form and plasma. Interna $\mathrm{J}$ resear Revi Pharm Appl Scienc r. I); I(r): $1 \cdot\{-11 \mathrm{~V}$.

r. Rang HP, Dale MM, Ritter JM, et al. Pharmacology. oth $^{\text {th }}$ edition. Edinburgh: Churchill Livingstone $r \ldots r$.

£. Wright MR, Axelson JE, Rurak DW, et al. Linearity of metoclopramide kinetics at doses of O-r. mg. Br $\mathrm{J}$ clin

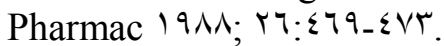

•. Khan A, Naqvi SS, Shoaib MH, et al. Validation and application of RP-HPLC method for the quantification of metoclopramide hydrochloride in oral formulations prepared 
for IVIVC studies. Pak J Pharm Sci r. Ir; ro( (1): Iro- I $\varepsilon$.

7. Radwan MA. Determination of metoclopramide in serum by HPLC assay and its application to pharmacokinetic study in rat. Analyt Lett 1991; r)( ( $\varepsilon): Y r 9 Y_{-}$ $r \leqslant 1$.

$\checkmark$. Sweetman S. Martindale: The complete drug reference. $r \varepsilon^{\text {th }}$ edition.

Pharmaceutical Press r...

London:

^. United States Pharmacopoeia. United States Pharmacopeial; roth edition. r... r r $r$ l pages.

१. British pharmacopoeia .Bernan Assoc; First edition . 1991. 1 1 19 pages.

1. Lee H, Ji HY, Kim HY, et al. Determination of metoclopramide in human plasma using hydrophilic interaction chromatography with tandem mass spectrometry. J Chromatogr B r..q; AVV:IVI $\tau_{-} I V Y$.

1). Riggs KW, Szeitz A, Rurak DW, et al. Determination of metoclopramide and two of its metabolites using a sensitive and selective gas chromatographic-mass spectrometric assay. J Chromatogr B Biomed Appl $199 \leqslant ; \pi 7 .(r): r 10-r 0$.

1r. Foda NH. Quantitative Analysis of Metoclopramide in Tablet Formulations by Hplc. Analyt Lett 199ะ; rv, ( $r): 0 \leqslant 9$. 009 .

1r. Wada M, Alkhalil SM, Nakashima K. Current HPLC Methods for Determination of Medicaments in Formulations and Biological Samples. J J Pharm Scien Y... ^; ' (').

I . Lamparczyk H, Chmielewska A, Konieczna L, et al. RPHPLC method with electrochemical detection for the determination of metoclopramide in serum and its use in pharmacokinetic studies. Biomed Chromatogr Y.. 1; 10:01r.01Y. 